\title{
1. The arc of racial stereotyping, prejudice and discrimination: social psychological perspectives
}

\section{Steven Fein}

If the arc of the moral universe bends toward justice, when it comes to racial justice in America one might ask what the angle of that bend is. In other words, what is the pace of progress? On the one hand, a close examination of legislation, opinion polls, sociological data and social psychological research indicates that racial prejudice and discrimination have been decreasing in the United States and in many other countries over the last 70 years, although elements of it may once again be on the rise, particularly in Western Europe. One of many dramatic examples of this trend concerns attitudes toward inter-racial marriage: in 1958, about 4 percent of respondents indicated approval of "marriages between white and colored people;" in 1995 approval of interracial marriage had risen to 48 percent, and in 2013 the rate was 87 percent. ${ }^{1}$ The degree to which white Americans endorse a variety of negative stereotypes about African Americans has similarly declined sharply according to studies conducted over the decades. ${ }^{2}$

The election of Barack Obama as the first African American president of the United States in 2008 was a significant sign of racial progress, as was his re-election in 2012. As Obama noted during his first inaugural address, his own father would not have been served in many restaurants in the nation's capital 60 years before, and now that father's son was being sworn in to the highest office in the land. That amount of progress in a person's lifetime is staggering.

On the other hand, when those of us who study stereotypes, prejudice and discrimination saw story after story in the popular media at the time of Obama's election heralding the dawn of a "postracial America," we knew how naive and wrong such notions were. To us, it came as little surprise that during his presidency Obama-along with his wife, Michelle-was the constant target of hateful racial epithets and blatant 
stereotypes hurled by politicians, police officials, journalists, political cartoonists, celebrities and ordinary citizens. During this time the spate of killings of unarmed African American men by police in several cities led to investigations that revealed persistent systemic racial discrimination. Data from archival analyses, surveys and experiments in which other variables are held constant continue to show how African American and Hispanic individuals suffer in comparison to white Americans in housing, employment, salaries, incarceration rates and a host of other important quality-of-life variables. ${ }^{3}$ The election of Donald Trump in 2016 to succeed Obama seemed to many to be a repudiation of the optimism concerning racial progress that Obama's election had inspired.

When African Americans and European Americans are asked to assess the degree or rate of racial progress, surveys and opinion polls routinely show significant differences in these estimates, in a predictable direction. Why do white Americans tend to perceive greater racial progress than Americans of color? Relatively obvious explanations may center on differences in lived experiences, as well as different motivations concerning how one wants to see the world. An additional, more subtle factor also contributes: these groups tend to have different reference points in mind when they begin to consider this question. The tendency among white Americans is to compare the present to where we were in the past, whereas the tendency among black Americans and other Americans of color is to compare the present to where we should be by this point. Experiments in which each group was induced to use the other group's typical reference point have shown dramatic changes in each group's assessments. $^{4}$

\section{DEFINITIONS AND LEVELS OF RACISM}

Given the complexity both of the data concerning trends in racial prejudice and discrimination and of the psychological factors underlying some of the perceptions and understandings of these issues, defining concepts such as prejudice or racism is no simple matter. Debates persist about how best to define the terms - how broad or specific they should be, whether they should focus on individual or institutional levels and so on. For example, one way to define racism is as prejudice and discrimination based on a person's racial background. Although many and probably most historians, sociologists and other scholars and activists would find fault with such a definition, this kind of definition resonates with many people, especially with white Americans. At the individual level, as this definition reflects, any of us can be racist toward anyone 
else. Much social psychological research does indeed focus at this individual level, exploring the many factors that create, exacerbate or mitigate individuals' biases as a function of a person's racial or ethnic background. The evidence is overwhelming that each of us is a perpetrator, and a target, of such biases.

What many people, particularly white Americans, often fail to appreciate is the extent to which racism exists at institutional and cultural levels. At the institutional and cultural levels, some people are privileged while others are disadvantaged. Aspects of various institutions and the culture more generally perpetuate this inequality, even if unintentionally. For example, institutions may unwittingly perpetuate racism by tending to accept or hire individuals who are similar or connected to the people who already are in the institution, and popular culture may signal what kinds of people are most and least valued. Therefore, another way to define racism is as institutional and cultural practices that promote the domination of one racial group over another.

Reactions to the shootings of unarmed African American men by the police in cities throughout the United States are one prominent example of the difficulty that many Americans have in discussing and understanding these issues because of differences in the conception of what racism is. Consider one of the most high-profile cases that occurred a decade and a half before the spate that many trace back to the killing of Michael Brown in Ferguson in the summer of 2014. In New York City on 4 February 1999, a West African immigrant named Amadou Diallo was spotted by four white police officers who thought he was acting suspiciously and that he matched the general description of a suspected rapist they were searching for. As they approached him, Diallo reached into his pocket and began pulling out his wallet. (When authorities in his native country stopped individuals, the individuals would often be expected to show them identification.) One of the officers yelled, "Gun!" The police fired at Diallo 41 times, hitting him with 19 of the bullets. Diallo lay dead in the vestibule; he did not have a weapon.

The killing and subsequent protests made all the papers and dominated the news for a period of time. The protests were peaceful, but the rhetoric on both sides was fierce. Against the charges of racism, many insisted that race had nothing to do with it, that the police did what almost anyone would do in a similar life-threatening situation in which one must decide in a split second whether a black object being pulled from a jacket is a gun or not-regardless of the apparent race of the person holding the object.

In 1999, the word "systemic" was not heard much in these debates. Today, there is more general awareness of institutional and cultural 
imbalances that result in the far greater likelihood that a black man would be harmed or killed in situations like these, and yet far too many people still see racism only at an individual level-if they are willing or able to see it at all. Indeed, discussions of systemic racism are likely to elicit counter-protests of reverse racism. Former Illinois Congressman Joe Walsh, for example, used social and news media to blame President Obama for the shooting of police officers in Dallas in the summer of 2016 because Obama had said the police are racist. When CNN's Don Lemon questioned Walsh about when Obama had labeled the police as racist, Walsh responded, "When he said there's systemic racism in the police department after the Minneapolis shooting, he's telling people on the streets that police officers are racist." Walsh added, "That kind of hating leads to what you got in Dallas." 5

Equating the identification of systemic racism with condemning the hearts and minds of individuals can lead to the kind of defensiveness and ignorance that Walsh's comments exemplify. One of the most important public missions of scholars on these issues is to educate the public about institutional and cultural levels of racism, sexism and other forms of prejudice and discrimination. Moreover, to have the most complete understanding of these issues and some of the strategies that can best attenuate them, it is essential to recognize the myriad, and often subtle, causes underlying them.

\section{MODERN AND IMPLICIT RACISM}

Examples of what some call old-fashioned racism-racism that is blatant, explicit and unmistakable - continue to be plentiful today. However, what some researchers call modern racism exists with much greater prevalence, but very often escapes recognition. This is a subtle form of prejudice that tends to surface when it is safe, socially acceptable or easy to rationalize. Modern racism is far more subtle and most likely to be present under the cloud of ambiguity. Like germs lurking beneath a seemingly clean countertop, stereotypes, prejudice and discrimination in contemporary life live under the surface to a much, much greater extent than most people realize. And like germs, their existence can have a profound effect on us, despite how hidden they may be.

According to theories of modern racism, and related theories and concepts such as microaggression, many people are racially ambivalent. They want to see themselves as fair, but they still harbor feelings of anxiety and discomfort about other racial groups. In these forms of racism, prejudice surfaces primarily under circumstances when the 
expression of prejudice is safe, socially acceptable and easy to rationalize because of its ambiguity. For example, several studies have found that white participants playing the role of jurors may be more likely to convict a black than a white defendant for a crime when the evidence is rather ambiguous, and thus one can justify either a guilty or not-guilty verdict for reasons having nothing to do with race. If, on the other hand, race is made to seem to be an important aspect of the case, then this bias may be eliminated or even reversed. ${ }^{6}$

These modern, ambivalent forms of racism are often evident in the "but some of my best friends are ..." excuse. That is, people establish their moral credentials of not being racist by demonstrating - to others or even to themselves - that they have good friends from the racial or ethnic group in question or that they have behaved in ways that were quite fair to members of this group. Having such good behavior to their credit gives people the license to take actions that might otherwise put them at risk for seeming prejudiced. Indeed, Anna Merritt and others found that people sometimes go out of their way to try to establish such credits, such as by rating an African American job candidate more positively, if they anticipate being in a situation later in which they might be judged as racist. $^{7}$

In just about any setting, examples of subtle but impactful discrimination can be found. Here is just a sample from recent research: in the workplace, businesses were less likely to call back job candidates based on their résumés if the name of the candidate was stereotypically African American rather than European American; in the classroom, students expected lower competence from a professor with a stereotypically African American rather than European American name, and professors were less likely to reply to email requests about research opportunities if the name of the sender seemed African-American rather than EuropeanAmerican; in the marketplace, car salespeople charged black customers higher prices than white customers for the same cars and iPods sold on the Internet received lower offers when held by black hands than white hands. $^{8}$

In one recent finding along these lines, for instance, Jason Okonofua and Jennifer Eberhardt gave school teachers information about an incident in which a middle-school child misbehaved (such as by sleeping in class and then not listening to the teacher when the teacher wakes him up). The teachers rated how troubled they would be by the behavior if they were the teacher and how severe the discipline of the child should be. Then they read about a second incident of misbehavior by this same child. The teachers then made the same judgments a second time. ${ }^{9}$

For half of the teachers, the name of the boy was, according to previous research, stereotypically black (Darnell or DeShawn), and for 
the others it was not (Jake or Greg). The researchers found no bias in teachers' judgments after the first infraction. That is, they reported being equally troubled and recommended equal punishments whether the boy seemed to be black or not. This would suggest no implicit racism here, right? But after the second infraction, a different story emerges. The teachers reported being more troubled, and recommended more severe discipline, after the second round of misbehavior if he apparently was black.

All these examples suggest two key points. First, although these biases are often very difficult to see, they are present in abundance, across a multitude of settings, ranging from the everyday to the profound. Second, it would be impossible to be sure that racism was behind any one person's specific behavior. There is just too much ambiguity or subtlety. But by looking at trends and by running experiments with careful controls, the underlying bias can be revealed.

Differences in individuals' degree of implicit racism, as assessed via measures such as the Implicit Association Test (IAT), correlate with a variety of attitudes and behaviors. For example, higher implicit racism by white participants in several studies predicted negative, unfriendly nonverbal behaviors in interracial interactions, such as physical distancing or lack of eye contact-actions that can make the other person feel disliked and that can lead to, for instance, poor performance in a job interview. ${ }^{10}$ A particularly disturbing, and growing, set of findings concerns the link between doctors' and other health care providers' implicit racism and their treatment of patients from racial and ethnic minority groups. ${ }^{11}$ For example, Janice Sabin and Anthony Greenwald found that doctors with stronger pro-white implicit bias were more likely to recommend prescribing pain-relieving medication after surgery for white patients, and less likely to do so for black patients, compared to physicians with less of a pro-white implicit bias score. ${ }^{12}$

\section{STEREOTYPE THREAT: A THREAT IN THE AIR}

One of the more tragic effects of stereotyping in contemporary life is on the intellectual performance and identity of its targets. Claude Steele proposed that in situations where a negative stereotype can apply to certain groups, members of these groups can fear being seen "through the lens of diminishing stereotypes and low expectations." ${ }^{13}$ Steele called this predicament stereotype threat, for it hangs like "a threat in the air" when the individual is in the stereotype-relevant situation. ${ }^{14}$ The predicament 
can be particularly threatening for individuals whose identity and selfesteem are invested in domains where the stereotype is relevant. Steele argued that stereotype threat plays a crucial role in influencing the intellectual performance and identity of stereotyped group members.

According to Steele's theory, stereotype threat can hamper achievement in academic domains in two ways. First, reactions to the "threat in the air" can directly interfere with performance-for example, by increasing anxiety and triggering distracting thoughts. Second, if this stereotype threat is chronic in the academic domain, it can cause individuals to disidentify from that domain - to dismiss the domain as no longer relevant to their self-esteem and identity.

Steele and others conducted a series of experiments in which they manipulated factors likely to increase or decrease stereotype threat as students took academic tests. For example, Steele and Joshua Aronson had black and white students from a highly selective university take a very difficult standardized verbal test. To some participants, it was introduced as a test of intellectual ability; to others, it was introduced as a problem-solving task unrelated to ability. Steele and Aronson reasoned that because of the difficulty of the test, all the students would struggle with it. If the test was said to be related to intellectual ability, however, the black students would feel the threat of a negative stereotype in addition to the stress of struggling with the test. In contrast, if the test was described simply as a research task and not a real test of intelligence, then negative stereotypes would be less applicable and the stereotype threat would be reduced. In that case, black students would be less impaired while taking the test. The results supported these predictions. ${ }^{15}$

Thus, a seemingly minor change in the setting - a few words about the meaning of a test - had a powerful effect on the black students' performance. In a second study, the researchers used an even more subtle manipulation of stereotype threat: whether or not the students were asked to report their race just before taking the test. Making them think about race for a few seconds just before taking the test impaired the performance of black students but had no effect on white students.

Since these original studies, research inspired by the theory of stereotype threat grew at a stunningly fast pace. The evidence for underperformance due to stereotype threat is quite strong and broad. It has been found both in the laboratory and in real-world settings, including schools and businesses. Although much of the research has documented the power of the effects of stereotype threat on African Americans and women, the scope of the research extends much further. Stereotype threats can affect any group for which strong, well-known negative stereotypes are relevant in particular settings. It should be pointed out 
that individuals can be affected by stereotype threat even if they do not believe in the negative stereotype. Just knowing about the stereotype seems to be enough, particularly if the individual identifies strongly with the targeted group and cares about performing well.

\section{UNDERLYING CAUSES}

One of the reasons that stereotypes, prejudice and discrimination persist is because they are caused by multiple factors. There are many sources fueling these problems, and they operate both independently and in tandem. In this section we consider just a small sample of these factors.

\section{Social Categories and Intergroup Conflict}

One basic fact is fundamental: we divide our social world into groups. As perceivers, we routinely sort each other into groups on the basis of gender, race, age and other common attributes in a process called social categorization. In some ways, social categorization is natural and adaptive. It allows us to form impressions quickly and use experience to guide new interactions. It also, however, leads us to overestimate the differences between groups and to underestimate the differences within groups.

Although categorizing humans is much like categorizing objects, there is a key difference. When it comes to social categorization, perceivers themselves are members or nonmembers of the categories they use. Groups that we identify with-our country, religion, political party, even our hometown sports team-are called ingroups, whereas groups other than our own are called outgroups. We see people in fundamentally different ways if we consider them to be part of our ingroup or outgroup. One consequence is that we exaggerate the differences between our ingroup and other outgroups, and this exaggeration of differences helps to form and reinforce stereotypes. Another consequence is a phenomenon known as the outgroup homogeneity effect, whereby perceivers assume that there is a greater similarity among members of outgroups than among members of one's own group. In other words, there may be many and subtle differences among "us," but "they" are all alike. Indeed, to most of us, "they" (that is, outgroup members) really do look more alike than "we" (ingroup members) do, in part because of the lack of familiarity and lack of diversity of experiences with outgroup members. Indeed, research using brain imaging has found that as soon as we categorize an unfamiliar person as a member of our ingroup or an 
outgroup, we immediately process information about them differently at even the most basic, neurological levels. ${ }^{16}$

\section{Fundamental Motives Between Groups}

The roots of dividing into ingroups and outgroups run quite deep in our evolutionary history, as early humans' survival depended on forming relatively small groups of similar others. A fundamental motive to protect one's ingroup and be suspicious of outgroups is therefore likely to have evolved. Consistent with this idea are the results of experiments that demonstrate that when people's basic motivations of self-protection are activated-such as in response to a threatening situation, economic scarcity, a scary movie, concerns about the flu or even being in a completely dark room-people are more prone to exhibit prejudice toward outgroups or to be especially hesitant to see possible outgroup members as part of one's ingroup. ${ }^{17}$ The flip side to the distrust of outgroups is the positive feelings we have toward being part of an ingroup. The feeling of connection and solidarity we have with our own group enhances our sense of control and meaning, and it is associated with numerous psychological as well as physical health benefits. ${ }^{18}$ When we are feeling threatened or uncertain, we become especially motivated to reaffirm our identification and closeness with an ingroup, which can make us feel more safe and secure. ${ }^{19}$

Direct competition for valuable but limited resources breeds hostility between groups. As a simple matter of economics, one group may fare better in the struggle for land, jobs or power than another group. A good deal of prejudice in the world is driven by competition-whether the competition is real or merely perceived. People tend to believe that their own nation, culture, language and religion are better and more deserving than others. Part of the reason for that is even more basic than real or perceived competition for finite resources, however. According to social identity theory, each of us strives to enhance our self-esteem, which has two components: (1) a personal identity and (2) various collective or social identities that are based on the groups to which we belong. In other words, people can boost their self-esteem through their own personal achievements or through affiliation with successful groups. This leads us to derive pride from our connections with others even if we don't receive any direct benefits from these others. It can also lead us to belittle "them" in order to feel secure about "us." Religious fervor, racial and ethnic conceit and aggressive nationalism may all fulfill this more negative side of our social identity. Two basic predictions arose from social identity theory: (1) threats to one's self-esteem heighten the need 
for ingroup favoritism, and (2) expressions of ingroup favoritism enhance one's self-esteem. Research generally supports these predictions.

Fein and Spencer proposed that threats to one's self-esteem can lead individuals to use available negative stereotypes to derogate members of stereotyped groups, and that by derogating others they can feel better about themselves. ${ }^{20}$ In one study, for example, Fein and Spencer gave participants positive or negative feedback about their performance on a test of social and verbal skills-feedback that temporarily bolstered or threatened their self-esteem. These participants then took part in what was supposedly a second experiment in which they evaluated a job applicant. All participants received a photograph of a young woman, her résumé and a videotape of a job interview. Half the participants were given information that suggested that the woman was Jewish. The other half was given information that suggested that the woman was not Jewish. On the campus where the study was held, there was a popular negative stereotype of the "Jewish American Princess" that often targeted upper-middle-class Jewish women from the New York area.

As predicted, there were two important results. First, among participants whose self-esteem had been lowered by negative feedback, they rated the woman more negatively if she seemed to be Jewish than if she did not, even though the videotaped job interview and credentials of the two women were the same. Second, participants who had received negative feedback and were given an opportunity to belittle the Jewish woman later exhibited a post-experiment increase in self-esteem-the more negatively they evaluated the Jewish woman, the better these participants felt about themselves. In sum, the results of this experiment suggest that a blow to one's self-image evokes prejudice and the expression of prejudice helps restore self-image.

Intergroup discrimination is achieved not only through negative reactions and behaviors toward outgroups but also through being especially favorable and helpful toward one's ingroups. In their aptly titled paper, "With malice toward none and charity toward some," Greenwald and Pettigrew propose that this is the more common type of intergroup bias, at least in the United States today. ${ }^{21}$ Malice toward outgroups tends to be frowned upon, whereas providing important advantages to one's ingroups may be more subtle and acceptable.

\section{Confirmation Biases and Self-fulfilling Prophecies}

Imagine learning that a mother yelled at a 16-year-old girl, a lawyer behaved aggressively and a Boy Scout grabbed the arm of an elderly woman crossing the street. Now imagine that a construction worker 
yelled at a 16-year-old girl, a homeless man behaved aggressively, and an ex-con grabbed the arm of an elderly woman crossing the street. Do very different images of these actions come to mind? This is a fundamental effect of stereotyping: stereotypes of groups influence people's perceptions and interpretations of the behaviors of group members. This is especially likely when a target of a stereotype behaves in an ambiguous way; perceivers reduce the ambiguity by interpreting the behavior as consistent with the stereotype.

The effect of stereotypes on individuals' perceptions is a type of confirmation bias, which involves people's tendencies to interpret, seek and create information that seems to confirm their expectations. Stereotypes can be reinforced also through the illusory correlation, a tendency for people to overestimate the link between variables that are only slightly or not at all correlated..$^{22}$ One kind of illusory correlation occurs when people overestimate the association between variables that are relatively rare. For example, if people read about a variety of criminal acts, most of which are committed by members of a majority group and some of which are committed by members of a particular minority group, they may overestimate the association between minority group status (a relatively rare group) and criminal behavior (a relatively rare behavior). This tendency can create or perpetuate negative stereotypes. Illusory correlations may also be produced through people's tendency to overestimate the association between variables they already expect to go together. For example, if perceivers who hold stereotypes about women being poor drivers witness 100 men and 100 women driving, and 10 percent of each group have an accident, they tend to overestimate the number of women and underestimate the number of men who had accidents. In other words, they see an association between gender and accidents that is not supported by the data.

Stereotypes also can create self-fulfilling prophecies. A self-fulfilling prophecy occurs when a perceiver's false expectations about a person cause the person to behave in ways that confirm those expectations. Stereotypes can trigger such behavioral confirmation. Consider a classic experiment by Carl Word and others involving a situation of great importance in people's lives: the job interview. White participants, without realizing it, sat farther away, made more speech errors, and held shorter interviews when interviewing black applicants than they did when interviewing white applicants. This colder interpersonal style, in turn, caused the black applicants to behave in a nervous and awkward manner. In short, the whites' racial stereotypes and prejudice actually hurt the interview performance of the black candidates. Since the black candidates' interview performance tended to be objectively worse than that of 
the white candidates, it seemed to confirm the interviewers' negative stereotypes-but this poor performance was caused by the interviewers, not the interviewees. ${ }^{23}$

\section{AUTOMATIC STEREOTYPE ACTIVATION AND THE SHOOTER BIAS}

Part of the power of stereotypes is that they can bias our perceptions and responses even if we don't personally agree with them. In other words, we don't have to believe a stereotype for it to trigger illusory correlations and self-fulfilling prophecies or to influence how we think, feel and behave toward group members. Sometimes just being aware of stereotypes in one's culture is enough to cause these effects. Moreover, stereotypes can be activated without our awareness.

Stereotypes can be activated implicitly and automatically, influencing subsequent thoughts, feelings and behaviors even among perceivers who are relatively low in prejudice. Even mere exposure to words subliminally - that is, presented so quickly that people aren't consciously aware of them-has been found to activate negative stereotypes among people who do not endorse these stereotypes, and this activation can in turn influence how they subsequently interpret information about a person's behavior. ${ }^{24}$

The issue of automatic activation of stereotypes and its effects can be seen in concrete terms by focusing on the kind of tragedy discussed earlier in this chapter: the shooting of unarmed African American men by the police. For example, Correll and others designed a video game for their experiment in which they had participants decide whether or not to "shoot" a target person who appeared on their computer screen. Some of these targets were white men and others were black men. Some of them held guns and others held harmless objects (such as a black cell phone or a wallet). If the target held a gun, the participants were supposed to hit a "shoot" key as quickly as possible. If he held a harmless object, they were to hit a "don't shoot" key as quickly as they could. These participants showed a bias consistent with racial stereotypes. If the target held a gun, they were quicker to press the "shoot" key if he was black than if he was white. If the target held a harmless object, they took longer to press the "don't shoot" key if he was black than if he was white. In addition, participants were more likely to mistakenly "shoot" an unarmed target if he was black than if he was white. ${ }^{25}$ These differences were of mere fractions of seconds, but they were statistically reliable. 
Several researchers have conducted related experiments with police officers as participants. In some of this research, police officers have shown a similar bias to mistakenly "shoot" a black target compared to a white target, and in some they have shown little or no racial bias in the decision to shoot. Reviewing all these studies, Joshua Correll and others concluded that even though police officers often are able to avoid these biases under testing conditions, when officers must make these decisions under conditions of fatigue, high stress, and distraction - the conditions officers often face when having to make real shoot-or-not decisionstheir ability to overcome stereotype-based biases are compromised, thus increasing the likelihood of the mistakes seen in the tragic incidents that sparked all this research. ${ }^{26}$

If individuals are racially biased in these perceptions and decisions, does that mean that they have racist attitudes and beliefs? The evidence thus far suggests that this may not be the case. For example, Correll et al. found that the magnitude of the racial bias in the decision to shoot was not related to participants' levels of racial prejudice as measured by a series of questionnaires. ${ }^{27}$ In addition, these researchers also found that African American participants showed the same bias against black targets as white participants did, again suggesting that racial prejudice is not necessarily reflected in this bias. Rather, awareness of the stereotype was a necessary factor, but endorsing it was not. Indeed, Correll et al. found that by manipulating the accessibility of stereotypes that associate blacks with danger in perceivers' minds (such as by having them first read newspaper articles about black or white criminals), they could strengthen or weaken this bias. ${ }^{28}$

\section{SOCIAL PSYCHOLOGICAL SOLUTIONS}

In this section, I turn from identifying many of the causes underlying stereotyping, prejudice and discrimination to focusing on some of the approaches that have been suggested for combating them.

\section{Intergroup Contact}

One of the many enduring ideas in Gordon Allport's classic book, The Nature of Prejudice, was the contact hypothesis, which states that under certain conditions, direct contact between members of rival groups will reduce intergroup prejudice. ${ }^{29}$ Four conditions are deemed ideal for intergroup contact to reduce intergroup prejudices: (1) the contact should occur in circumstances that give the two groups equal status; (2) the 
contact should involve one-on-one interactions among individual members of the groups; (3) members of the groups should join together in cooperative activities in an effort to achieve superordinate goals; and (4) the social norms, defined in part by relevant authorities, should favor intergroup contact.

These conditions of contact often are not met, and the efficacy of this approach seemed in question when the early years of desegregation in schools-under conditions that tended to fall far short of the ideal conditions outlined in the theory-did not result in reduced intergroup hostilities. Fortunately, experts on the contact hypothesis today suggest a much more optimistic picture. In a series of meta-analyses involving more than 500 studies and a quarter of a million participants in 38 nations, Pettigrew and Tropp found reliable support for the benefits of intergroup contact in reducing prejudice, particularly when the contact satisfies at least some of the conditions mentioned above. These researchers propose that contact reduces prejudice by (1) enhancing knowledge about the outgroup; (2) reducing anxiety about intergroup contact; and (3) increasing empathy and perspective taking. ${ }^{30}$

\section{Shared Identities}

The Common Ingroup Identity Model developed by Gaertner and Dovidio proposes that if members of different groups recategorize themselves as members of a more inclusive superordinate group, intergroup attitudes and relations can improve. ${ }^{31}$ By recognizing their shared categorization, "they" become "we," and a common ingroup identity can be forged. It is worth noting that at least in some contexts, individuals from minority groups or groups that have less power in a society tend not to feel as positively as majority group members do about recategorizing their groups into one common ingroup. A group with smaller numbers or less power may feel overwhelmed with a sense of lost identity if they merge completely with a larger or more powerful group. Instead, members of these groups sometimes prefer or benefit more from dualidentity categorizations, in which their distinctiveness as a member of their specific group is preserved but in which they recognize their connection and potential for cooperation with the majority or more powerful group. ${ }^{32} \mathrm{~A}$ key point remains, though, that seeing connections between the groups and ways in which their identities are shared is essential. 


\section{Trust, Belonging and Reducing Stereotype Threat}

Many dozens of experiments on Claude Steele's theory of stereotype threat and its effects on academic achievement and identity were published soon after the theory was introduced in the mid-1990s, and in virtually each of them the negative effects of stereotype threat were reduced significantly or eliminated completely in some conditions of the study. Often this was achieved with seemingly very minor-but important-changes in the setting. A theme running through many of the successful interventions against stereotype threat effects is that the individuals feel a sense of trust and safety in the situation. That is, in this particular setting they feel that they are not the target of others' low expectations and they do not have to be concerned with unfairness or other obstacles that would otherwise distract, worry or discourage them.

The importance of establishing this trust is evident in the results of an experiment by Cohen et al. Students in this study performed a writing task and then received criticism of their writing from a reviewer they presumed to be white. Compared to white students, black students tended to respond less constructively and were more likely to dismiss the criticism as biased against them. These negative reactions to the criticism were eliminated, however, if the reviewer who gave the criticism added two elements: (1) he made it clear that he had high standards, and (2) he assured the students that he was confident that they had the capacity to achieve those standards. This combination of factors made the students trust the criticism and gave them the sense that they had a fair shot at succeeding at the task. ${ }^{33}$

In addition to causing distrust, one of the most powerful ways in which stereotype threat undermines students is that it reduces their sense of belonging. That is, targeted students are likely to feel that people like me do not belong here, such as in a particular major, school or career. Researchers have applied social psychological techniques to create interventions outside the lab that have had truly remarkable success with students in a number of schools. ${ }^{34}$ For example, Walton and Cohen gave some first-semester African American students at a predominately European American college information designed to reduce feelings of uncertainty about their sense of belonging at the university. They read that it is quite typical of most students - regardless of their gender, race or ethnicity - to go through periods of social stress and uncertainty during their freshman year, and that these struggles tend to go away soon after their first year. Walton and Cohen found that giving this information to African American students during their first semester at school raised their grade-point averages significantly higher relative to other African 
American students who were not given this information. ${ }^{35}$ Especially impressive was that this effect lasted through their entire college experience. Walton and Cohen used a similar type of intervention that dramatically improved the performance of female students in majors dominated by male students at an engineering school. ${ }^{36}$

\section{CONCLUSIONS}

Social psychology did not exist as a field of study during Reconstruction, and the research reported in this chapter focuses on trends and factors underlying racial stereotyping, prejudice, and discrimination in the late twentieth and early twenty-first centuries. However, applications of this research to the earlier eras on which this volume focuses can, and perhaps should, be made.

The fear and social costs associated with being considered racist are, obviously, far greater today than in the eighteenth and nineteenth centuries, and these concerns today fuel much of the ambivalence and implicit nature that characterizes so much more of the racial prejudice and discrimination of the current era. But surely this kind of ambivalence, these conflicting motives, these psychological forces that operate on very different levels, are all evident in the founding of the nation and through Reconstruction and beyond. The founders and the framers of the Declaration of Independence and the Constitution clearly struggled with these conflicts, forging compromises that had the inevitability of ultimate failure and collapse always present. The great problem of race, that enduring burden and perhaps original sin of the United States, has had at its core many of the social psychological factors that contemporary social psychological research continues to reveal, albeit manifested often in very different ways.

The idea of a people freed from slavery, and given political and economic opportunities, was of course an enormous threat to many whites in the years before, during, and after Reconstruction. The perception of competition for finite resources is one of the triggers this chapter has identified for intergroup hostilities and prejudices, and this perception no doubt provided fierce motivation for the American South in particular to rebel against the possibility of equality for the races. The more subtle but perhaps equally powerful role of social identity was also critical, as it remains today. The esteem of the groups to which we strongly identify is elementally important to how we see ourselves as individuals, and a blow, even a symbolic rather than real economic or political blow, to the standing of our racial or ethnic group can unleash a strong and aggressive 
backlash. Years of research on social identity theory have provided numerous demonstrations of this tendency, and the lessons from this work can help us understand some of the desperation behind whites aggressively clinging to every opportunity to deny gains by other racial groups, even among whites who simultaneously believe in the basic tenets of egalitarianism and meritocracy that they would claim to be central to the American philosophy.

The illogic of holding these contradictory impulses does not necessarily create for individuals the cognitive dissonance we might think would be inevitable, for several reasons. Our psychology allows many of us to compartmentalize attitudes, beliefs and behaviors with impressive facility, so that the one hand, figuratively speaking, does not know what the other is doing. Our motives and even behaviors can work in nonconscious, implicit ways, so that contradictions of principle escape unnoticed. In reacting in a biased way to a particular person, a particular small group or a particular policy, we may be truly unaware of this bias, and our sense of ourselves as fair-minded, logical individuals remains intact. This is not simply denial. A much more complex, and sustaining, set of psychological factors makes these contradictions and ambivalences possible.

Among the other factors that sustain these biases is our tendency to make attributions - that is, explain the causes of behavior-in biased ways. Through our proclivity to fall prey to various attributional biases even when we are unmotivated to do so, white Americans often would, during the days of Reconstruction or today, attribute the failure of a black man to his internal weaknesses, and the success of a black man to the fluke of random chance or to a situational advantage that was not of his own making. Similarly, through our tendencies toward illusory correlations, again without conscious awareness or motivation, white Americans could grossly overestimate the association between negative behaviors and membership in a minority group, and grossly underestimate the association between such behaviors and membership in a majority group. (Consider, for example, the tendency today of many Americans to dramatically overestimate the frequency of violent crimes committed by minority groups toward whites.) Research has shown that this tendency occurs even when the groups are fictitious and individuals have no reason to see them in a positive or negative way. Add an actual history of conflict and a motivation to preserve a status quo or protect against a perceived threat, and the tendency can be heightened dramatically.

These are but a small sample of the social psychological processes and factors that can explain the existence and persistence of racism across the 
years, some of which are far more subtle than the more obvious causes of which most people are aware. Just as it is a mistake to assert that racism does not exist in individuals who have no evil intentions in their conscious minds or hearts, it also is an oversimplification to assume that evidence of racism must therefore imply the existence of such intentions.

Contemporary social psychological research does, however, provide reason to believe that the arc is bending toward more racial justice. As sociocultural norms have shifted to make racism and other forms of unequal and insensitive treatment of people more likely to be challenged and attacked, the psychological equations for preserving one's selfesteem and social identity status must shift as well. Similarly, the automatic, cognitive processes that lead to particular kinds of biased processing of information similarly become less efficient and effective. In my own lab, for example, I have found that when individuals receive a threat to their self-esteem, such as by getting feedback suggesting that their competence in some important domain (unrelated to issues of race or ethnicity) may be inferior, they often try-without conscious awareness - to reclaim some superiority by derogating members of racial or ethnic outgroups. I have also found, however, that if these individuals are made to perceive that the local norms in their community strongly support an anti-racist sensibility, these individuals may instead respond to a threat by exhibiting attitudes and behaviors that promote rather than derogate these racial or ethnic outgroups. In other words, to reclaim a sense of positive self-worth, these individuals act in ways consistent with what is valued in their local groups, and if those ways involve intergroup support rather than competition, the path to achieve that self-worth has changed.

This is but one example, and its positive results do not, of course, negate the many factors that work to preserve racial stereotyping, prejudice and discrimination, but it may reflect one of a growing number of factors that contribute to a shifting of the sands. The struggle remains to appeal to "the better angels of our nature," as Lincoln described it at the closing of his first inauguration address, but there is more momentum toward these angels and away from our inner demons than ever before.

\section{NOTES}

1. Frank Newport, "In U.S., 87\% approve of black-white marriage, vs. 4\% in 1958," Gallup, 2015, Available at: http://www.gallup.com/poll/163697/approve-marriage-blacks-whites. aspx.

2. John F. Dovidio, John C. Brigham, Blair T. Johnson and Samuel L. Gaertner, "Stereotyping, prejudice, and discrimination: another look," in Stereotypes and Stereotyping, eds 
C. Neil Macrae, Charles Stangor and Miles Hewstone (New York: Guilford, 1996): 276-319; Daniel Katz and Kenneth Braly, "Racial stereotypes of one hundred college students," The Journal of Abnormal and Social Psychology, 28 (1933): 280-90; Stephanie Madon, Max Guyll, Kathy Aboufadel, Eulices Montiel, Alison Smith, Polly Palumbo and Lee Jussim, "Ethnic and national stereotypes: the Princeton trilogy revisited and revised," Personality and Social Psychology Bulletin, 27 (2001): 996-1010.

3. Ryan Gabrielson, Ryann Grochowski Jones and Eric Sagara, "Deadly force, in black and white," ProPublica, 10 October 2014, Available at: http://www.problica.org/article/deadlyforce-in-black-and-white; Sari Horwitz, "FBI director acknowledged 'hard truths' about racial bias in policing," The Washington Post (13 February 2015), Available at: https:// www.washingtonpost.com/world/national-security/fbi-director-acknowledges-hard-truthsabout-racial-bias-in-policing/2015/02/12/023c6c6e-b2c6-11e4-854b-a38d13486ba1_story. html?utm_term=.59006514a0c4; Devah Pager and Hana Shepherd, "The sociology of discrimination: racial discrimination in employment, housing, credit, and consumer markets," Annual Review of Sociology, 34 (2008): 181-209; Barbara Reskin, "The race discrimination system," Annual Review of Sociology, 38 (2012): 17-35.

4. Amanda B. Brodish, Paige C. Brazy and Patricia G. Devine, "More eyes on the prize: variability in White Americans' perceptions of progress toward racial equality," Personality and Social Psychology Bulletin, 34 (2008): 513-27; Richard P. Eibach and Joyce Ehrlinger, "Keep your eyes on the prize': reference points and racial differences in assessing progress toward equality," Personality and Social Psychology Bulletin, 32 (2006): 66-77.

5. Tom LoBianco and Olivia Beavers, "Ex-Rep. Joe Walsh defends tweet threatening 'war' on Obama," CNN, 8 July 2016, Available at: www.cnn.com/2016/07/08/politics/joe-walshobama-war-tweet.

6. Donald O. Bucolo and Ellen S. Cohn, "Playing the race card: making race salient in defense opening and closing statements," Legal and Criminological Psychology, 15 (2010): 293-303; Steven Fein and Steven J. Spencer, "Prejudice as self-image maintenance: affirming the self through derogating others," Journal of Personality and Social Psychology, 73 (1997): 31-44; Samuel R. Sommers and Phoebe C. Ellsworth, "'Race salience' in juror decision-making: misconceptions, clarifications, and unanswered questions," Behavioral Sciences and The Law, 27 (2009): 599-609.

7. Anna C. Merritt, Daniel A. Effron, Steven Fein, Kenneth K. Savitsky, Daniel M. Tuller and B. Benoît Monin, "The strategic pursuit of moral credentials," Journal of Experimental Social Psychology, 48 (2012): 774-7.

8. Anish Bavishi, Juan Madera and Mikki Hebl, "The effect of professor ethnicity and gender on student evaluations: judged before met," Journal of Diversity in Higher Education, 3 (2010): 245-56; Zachary W. Brewster and Michael Lynn, "Black-white earnings gap among restaurant servers: a replication, extension, and exploration of consumer racial discrimination in tipping," Sociological Inquiry, 84 (2014): 545-69; Jennifer L. Doleac and Luke C.D. Stein, "The visible hand: race and online market outcomes," The Economic Journal, 123 (2013): F469-F492; Jennifer L. Eberhardt, Paul G. Davies, Valerie J. Purdie-Vaughns and Sheri Lynn Johnson, "Looking deathworthy: perceived stereotypicality of black defendants predicts capital-sentencing outcomes," Psychological Science, 17 (2006): 383-6; Eden B. King, Juan M. Madera, Mikki R. Hebl, Jennifer L. Knight and Saaid A. Mendoza, "What's in a name? A multiracial investigation of the role of occupational stereotypes in selection decisions," Journal of Applied Social Psychology, 36 (2006): 1145-59; Katherine L. Milkman, Akinola Modupe and Dolly Chugh, "What happens before? A field experiment exploring how pay and representation differentially shape bias on the pathway into organizations," Journal of Applied Psychology, 100 (2015): 1678-712; Whitney Botsford Morgan, Katherine B. Elder and Eden B. King, "The emergence and reduction of bias in letters of recommendation," Journal of Applied Social Psychology, 43 (2013): 2297-306.

9. Jason A. Okonofua and Jennifer L. Eberhardt, "Two strikes: race and the disciplining of young students," Psychological Science (2015): 617-24. 
10. Anthony G. Greenwald, T. Andrew Poehlman, Eric Luis Uhlmann and Mahzarin R. Banaji, "Understanding and using the Implicit Association Test: III. Meta-analysis of predictive validity," Journal of Personality and Social Psychology, 97 (2009): 17-41.

11. Irene V. Blair, Nilanjana Dasgupta and Jack Glaser, "Implicit attitudes," in APA Handbook of Personality and Social Psychology, Volume 1: Attitudes and Social Cognition, eds Mario Mikulincer, Phillip R. Shaver, Eugene Borgida and John A. Bargh (Washington, DC: American Psychological Association, 2015): 665-91; Louis A. Penner, Nao Hagiwara, Susan Eggly, Samuel L. Gaertner, Terrance L. Albrecht and John F. Dovidio, "Racial healthcare disparities: a social psychological analysis," European Review of Social Psychology, 24 (2013): 70-122; Kendra L. Schaa, Debra L. Roter, Barbara B. Biesecker, Lisa A. Cooper and Lori H. Erby, "Genetic counselors' implicit racial attitudes and their relationship to communication," Health Psychology, 34 (2015): 111-19.

12. Janice A. Sabin and Anthony G. Greenwald, "The influence of implicit bias on treatment recommendations for 4 common pediatric conditions: pain, urinary tract infection, attention deficit hyperactivity disorder, and asthma," American Journal of Public Health, 102 (2012): 988-95.

13. Claude M. Steele, "Thin ice: 'stereotype threat' and black college students," Atlantic Monthly, 284, August 1999, 44.

14. Claude M. Steele, "A threat in the air: how stereotypes shape intellectual identity and performance," American Psychologist, 52 (1997): 613-29.

15. Claude M. Steele and Joshua Aronson, "Stereotype vulnerability and the intellectual test performance of African Americans," Journal of Personality and Social Psychology, 69 (1995): 797-811.

16. Jay J. Van Bavel, Leor M. Hackel and Y. Jenny Xiao, "The group mind: the pervasive influence of social identity on cognition," in New Frontiers in Social Neuroscience, eds Jean Decety and Yves Christen (Cham, Switzerland: Springer International Publishing, 2014), 41-56.

17. Anastasia Makhanova, Saul L. Miller and Jon K. Maner, "Germs and the out-group: chronic and situational disease concerns affect intergroup categorization," Evolutionary Behavioral Sciences, 9 (2015): 8-19; Jon K. Maner, Saul L. Miller, Justin H. Moss, Jennifer L. Leo and Ashby E. Plant, "Motivated social categorization: fundamental motives enhance people's sensitivity to basic social categories," Journal of Personality and Social Psychology, 103 (2012): 70-83.

18. Katharine H. Greenaway, Alexander S. Haslam, Tegan Cruwys, Nyla R. Branscombe, Renate Ysseldyk and Courtney Heldreth, "From 'we' to 'me': group identification enhances perceived personal control with consequences for health and well-being," Journal of Personality and Social Psychology, 109 (2015): 53-74; Dario Páez, Bernard Rimé, Nekane Basabe, Anna Wlodarczyk and Larraitz Zumeta, "Psychosocial effects of perceived emotional synchrony in collective gatherings," Journal of Personality and Social Psychology, 108 (2015): 711-29.

19. Mina Cikara and Jay J. Van Bavel, "The neuroscience of intergroup relations: an integrative review," Perspectives on Psychological Science, 9 (2014): 245-74; Michael A. Hogg, "From uncertainty to extremism: social categorization and identity processes," Current Directions in Psychological Science, 23 (2014): 338-42.

20. Fein and Spencer, "Prejudice as self-image maintenance."

21. Anthony G. Greenwald and Thomas F. Pettigrew, "With malice toward none and charity for some: ingroup favoritism enables discrimination," American Psychologist, 69 (2014): 669-84.

22. David L. Hamilton and Terrence L. Rose, "Illusory correlation and the maintenance of stereotypic beliefs," Journal of Personality and Social Psychology, 39 (1980): 832-45.

23. Carl O. Word, Mark P. Zanna and Joel Cooper, "The nonverbal mediation of self-fulfilling prophecies in interracial interaction," Journal of Experimental Social Psychology, 10 (1974): 109-20.

24. Patricia G. Devine, "Stereotypes and prejudice: their automatic and controlled components," Journal of Personality and Social Psychology, 56 (1989): 5-18; Steven Fein, 
Etsuko Hoshino-Browne, Paul G. Davies and Steven J. Spencer, "Self-image maintenance goals and sociocultural norms in motivated social perception," in Motivated Social Perception: The Ontario Symposium, vol. 9, eds Steven J. Spencer, Steven Fein, Mark P. Zanna and James M. Olson (Mahwah, NJ: Erlbaum, 2003): 21-44.

25. Joshua Correll, Bernadette Park, Charles M. Judd and Bernd Wittenbrink, "The police officer's dilemma: using ethnicity to disambiguate potentially threatening individuals," Journal of Personality and Social Psychology, 83 (2002): 1314-29.

26. Joshua Correll, Sean M. Hudson, Steffanie Guillermo and Debbie S. Ma, "The police officer's dilemma: a decade of research on racial bias in the decision to shoot," Social and Personality Psychology Compass, 8 (2014): 201-13.

27. Correll et al., "The police officer's dilemma: using ethnicity to disambiguate potentially threatening individuals."

28. Joshua Correll, Bernadette Park, Charles M. Judd and Bernd Wittenbrink, "The influence of stereotypes on decisions to shoot," European Journal of Social Psychology, 37 (2007): 1102-17.

29. Gordon W. Allport, The Nature of Prejudice (Reading, MA: Addison-Wesley, 1954).

30. Thomas F. Pettigrew and Linda R. Tropp, "Does intergroup contact reduce prejudice? Recent meta-analytic findings," in Reducing Prejudice and Discrimination: The Claremont Symposium on Applied Social Psychology, ed. Stuart Oskamp (Mahwah, NJ: Erlbaum, 2000): 93-114; Thomas F. Pettigrew and Linda R. Tropp, "A meta-analytic test of intergroup contact theory," Journal of Personality and Social Psychology, 90 (2006): 751-83; Thomas F. Pettigrew and Linda R. Tropp, "How does intergroup contact reduce prejudice? Meta-analytic tests of three mediators," European Journal of Social Psychology (2008): 922-34.

31. Samuel L. Gaertner and John F. Dovidio, "Common ingroup identity model," in Encyclopedia of Group Processes and Intergroup Relations, vol. 1, eds John M. Levine and Michael A. Hogg (Thousand Oaks, CA: Sage, 2010): 119-22.

32. John F. Dovidio, Tamar Saguy, Samuel L. Gaertner and Erin L. Thomas, "From attitudes to (in)action: the darker side of 'we'," in Beyond Prejudice: Extending the Social Psychology of Conflict, Inequality and Social Change, eds John Dixon and Mark Levine (New York: Cambridge University Press, 2012): 248-68.

33. Geoffrey L. Cohen, Claude M. Steele and Lee D. Ross, "The mentor's dilemma: providing critical feedback across the racial divide," Personality and Social Psychology Bulletin, 25 (1999): 1302-18.

34. Gregory M. Walton, "The new science of wise psychological interventions," Current Directions in Psychological Science, 23 (2014): 73-82.

35. Gregory M. Walton and Geoffrey L. Cohen, "A brief social-belonging intervention improves academic and health outcomes of minority students," Science, 331 (2011): 1447-51.

36. Gregory M. Walton, Christine Logel, Jennifer M. Peach, Steven J. Spencer and Mark P. Zanna, "Two brief interventions to mitigate a 'chilly climate' transform women's experience, relationships, and achievement in engineering," Journal of Educational Psychology, 107 (2015): 468-85. 